Pengembangan Rekayasa dan Teknologi, Vol 14, No. 1, Juni 2018, pp 24-27

p-ISSN: $1410-9840$ \& e-ISSN: 2580-8850

http://journals.usm.ac.id/index.php/jprt/index

\title{
PENGAMANAN DATA PADA APLIKASI SIJALU UNIVERSITAS SEMARANG DENGAN METODE REMOTE BACKUP \& RESTORE
}

\author{
${ }^{1}$ Whisnumurti Adhiwibowo, ${ }^{2}$ M. Sani Suprayogi, ${ }^{3}$ Atmoko Nugroho \\ ${ }^{1,2,3}$ Fakultas Teknologi Informasi dan Komunikasi \\ ${ }^{1}$ Whisnu@usm.ac.id, ${ }^{2}$ yogie@usm.ac.id, ${ }^{3}$ atmoko@usm.ac.id
}

\begin{abstract}
Security of web applications should include a variety of ways, one of which is concerned about data security. Websites that already have a lot of users it is proper to consider the backup and restore strategy to prevent data loss. Besides the use of backup and restore is done on a scheduled basis should also be done at any time, so it is necessary to do the planning and use of the right tools so that the implementation is easier. Journal of Information Systems (SIJALU) University of Semarang contains data of scientific publications from researchers at tire University of Semarang and other campuses. Currently SIJALU not yet have a strategy for the prevention of data loss, this study intends to design and produce a data security benefits of using remote backup and restore. This research is expected with the data stored in SIJALU can be maintained.
\end{abstract}

Keyword: Data Security,Sijalu, Remote Server, Backup Restore

\section{Pendahuluan}

Institusi pendidikan telah mulai memanfaatkan Teknologi Informasi dalam pelaksanaan Tridharma Perguruan Tinggi. Namun pada praktiknya masih menemui beberapa hambatan seperti infrastruktur yang kurang memadai, layanan yang tidak terintegrasi, kurangnya kompetensi dalam memanajemen, dan perlunya standarisasi dalam strategi implementasi IT [1]. Cloud computing, sebagaimana yang disebutkan oleh Zhang ct al. [2] merupakan pengembangan Grid Computing yang memaksimalkan penggunaan sejumlah perangkat IT sekaligus akan menurunkan konsumsi energi. Hal inilah yang menarik minat penulis pada penelitian sebelumnya yaitu membahas strategi implementasi cloud computing di institusi pendidikan, dengan studi kasus Universitas Semarang (USM) [3].

Penelitian cloud computing pada sektor pendidikan (Cloud Education) memiliki karakteristik yang berbeda dibandingkan dengan sektor industri ataupun pemerinlahan, antara Iain pada masalah IT Governance dan IT Infrastructure [1]. Untuk hal IT Infrastructure, penelitian mengenai strategi implementasi cloud computing di sektor pendidikan telah dilakukan dimana penelitian tersebut berhasil mengimplementasikan cloud computing dengan hasil nyata berupa pengurangan jumlah server fisik vang dapat menghemat dari sisi penggunaan energi dan biaya. Namun belum dibahas metode backup \& server untuk mengamankan infrastruktur cloud yang telah ada [3].

Penelitian yang berkaitan dengan aplikasi web masih terus dilakukan, fokus penelitian juga sudah mengarah pada hal keamanan pada aplikasi web. Sebelumnya, $\mathrm{He}$ et al. [4] telah mengusulkan mengenai pengamanan website dengan berorientasi metode backup \& recovery secara remote, dengan tujuan pengguna dapat menentukan sendiri teknik backup yang dikehendaki. Latta and Galanda [5] juga telah mengusulkan rancangan metode network backup \& restore namun untuk skala enterprise dan penggunaan aplikasi berbayar.Sampaio and Bernardino [6] telah melakukan perbandingan beberapa aplikasi backup yang bersifat open source dengan hasil Bacula dan Amanda [6] menempati peringkat teratas dalam perbandingan tersebut. Penelitian ini akan mengutamakan remote backup \& recovery dengan aplikasi yang bersifat open source.

Universitas Semarang (USM) telah mengimplementasikan cloud computing pada beberapa aplikasi berbasis web, namun hingga saat ini belum memiliki backup system untuk mengantisipasi masalah kehilangan data. Aplikasi berbasis web harus memperhatikan lima ancaman dari peretas, yaitu : remote code execution, cross-site scripting (XSS), SQL injection $(S Q U)$, dan PHP configuration and file system attacks. Hal ini merupakan hambatan. sesuai yang disebutkan oleh Cenka et al. [1] yakni kurangnya kompetensi dalam manajemen.

Backup \& recovery yang berfungsi untuk melindungi kehilangan data ketika sebuah sistem terkena serangan hacker. Beberapa metode backup dan recovery telah dikenalkan agar dapat menyesuaikan dengan kasus yang dihadapi. Aplikasi yang berjalan dicloud computing Universitas Semarang (USM) saat ini hanya dijalankan pada satu buah server yang berlokasi di ruang server, sehingga apabila terjadi bencana atau force major maka tidak terdapat backup untuk melakukan recovery. Salah satu aplikasi yang terdapat dalam server tersebut adalah Sistem Informasi Jumal Ilmiah (SIJALU) yang berfungsi untuk mempublikasikan hasil penelitian dengan alamat http: journals.usm ac.id. Maka dibutuhkan penelitian untuk membuat backup server yang terpisah dari ruang server 
yang nantinya dapat melakukan remote connection dalam melakukan backup \& recovery.

\section{2 .Metode Penelitian}

\section{Metode Pengembangan Sistem}

Pengembangan jaringan komputer merupakan kegiatan yang terus berkesinambungan sehingga tahap perencanaan merupakan hal terpenting. Model PPDIOO (Prepare, Plan, Design, Implement, Operate, and Optimize) [7] dinilai metode yang tepat untuk memulai pengembangan jaringan komputer,adapun tahapannya sebagai berikut:

\section{Prepare}

Pada tahap ini peneliti menentukan strategj dan model bisnis jaringan cloud pada Universitas Semarang, sehingga dapat menentukan rencana pada tahap selanjutnya. Pengumpulan data merupakan bagian dari tahap prepare supaya dapat diketahui permasalahan secara lebih mendalam, adapun cara yang dilakukan sebagai berikut:

a. Peneliti melakukan studi literature dengan membaca buku, jumal, artikel Internet,dan catatan-catatan yang menunjang metode backup \& recovery.

b. Peneliti mengamati kondisi ruang server dan lokasi calon server cadangan beserta melakukan pengecekan pada infirastruktur Intranet yang tersedia. Selain itu juga melakukan pengecekan terhadap fisik server yang akan digunakan sebagai server cadangan.

2. Plan

Tahap ini peneliti melakukan perencanaan kebutuhan backup \& recovery, menganalisis permasalahan, dan menentukan waktu pelaksanaan.

\section{Design}

Pada tahap ini, peneliti mulai membuat rancangan desain topologi antara ruang server dengan server cadangan secara mendetail yang akan diimplementasikan pada jaringan Intranet USM.

\section{Implement}

Tahap ini peneliti melakukan implementasi terhadap rencana dan desain yang telah dilakukan sebelumnya. 5. Operate

Tahap operate merupakan tahapan yang cukup menentukan, karena pada tahap ini sistcm backup \& recovery harus sudah berjalan dan diikuti dengan melakukan monitoring terhadap jaringan tersebut. 6. Optimize

Peneliti melakukan optimasi dan memperbaiki apabila terdapat permasalah. Selain itu juga sembari meningkatkan performa dan menjaga stabilitas jaringan.

\section{Hasil dan Pembahasan Persiapan}

Tahapan ini merupakan tahap awal, yaitu persiapan (Prepare) pada metode PPDIOO [7] yang bertujuan untuk mengindentifikasi model bisnis jaringan cloud Universitas Semarang. Saat ini Universitas Semarang telah mengoperasikan layanan cloud dengan model IaaS (Infrastructure as a Services) untuk melayani kebutuhan server bagi peneliti dan programmer untuk menjalankan berbagai aplikasi. Server cloud ditempatkan di ruang server Universitas Semarang, berada satu rack dengan server lain. Aplikasi cloud management yang digunakan adalah Proxmox VE versi 3.2-4. Layanan cloud USM telah mengoperasikan 15 virtual server yang masing-masing diberikan IP Private 10.0.0.0/24 dengan menggunakan metode portforwarding. NAT, dan reverse-proxy supaya setiap virtual server dapat diakses dari internet meskipun virtual server tersebut menggunakan IP Private. Salah satu virtual server yang berjalan adalah layanan Sistem Informasi Jurnal Ilmiah Universitas Semarang (SIJALU) yang berisi hasil penelitian dosen dan mahasiswa yang beralamat di http://journals.usm.ac id.

\section{Perencanaan}

Tahap kedua adalah perencanaan ( plan )[7], dimana tahapan ini untuk mengindentifikasi masalah dan merencanakan strategi backup yang tepat untuk layanan SIJALU Universitas Semarang. Berdasarkan hasil pengamatan di lokasi, saat ini layanan cloud USM bclum memiliki strategi backup, baik yang sifatnya on-demand ataupun automatic. Hal ini sangat riskan karena layanan SIJALU inenvimpan data-data penelitian yang telah terindex di berbagai lembaga pengindex jumal, sehingga perlu dibuatkan rencana backup dan restore. Terdapat beberapa metode yang umum digunakan untuk melakukan backup \& restore.

Berbagai metode tersebut perlu menyesuaikan dengan kondisi dan kemampuan infrastruktur yang tersedia, sehingga dapat menentukan strategi yang sesuai. Ellingwood [8] menyebutkan pada dasamya terdapat 2 (dua) cara untuk mengamankan data, yaitu Redundancy dan Racking Up. Backing Up atau sering disebut Backup yang berarti tidak hanya mencadangkan sekumpulan data saja, tetapi metode ini juga dapat mencadangkan keseluruhan sistem. Sehingga misalnya terjadi masalah pada level server, maka proses ini dapat melakukan restore data keseluruhan sehingga layanan dapat berjalan kembali. Metode Backup ini membutuhkan waktu downtime yang bervariasi tergantung dari besaran restore data yang dilakukan.

Pada metode backup, masih terbagi menjadi beberapa cara. Antara lain File-Level Backup. Block-Level Backup, Versioning Backup, dan System-Level Backup. Berdasarkan pengamatan di lokasi, kebutuhan untuk backup data pada layanan SIJALU adalah pengamanan data penelitian yang tersimpan di dalamnya, sehingga metode backup yang dipilih adalah file-level backup. Pada metode ini terdapat cara manual atau menggunakan perintah Rsync yang berfungsi untuk membuat backup dengan fleksibel, seperti penjadwalan dan sebagainya. Namun untuk mempermudah prosesnya perlu menggunakan aplikasi BackupPC karena kemudahan dalam konfigurasi.

\section{Perancangan}

Tahapan selanjutnya adalah perancangan (design) 
[7] . Pcnulis menggunakan aplikasi BackupPC untuk membantu proses backup A restore. Aplikasi ini dapat dapat melakukan backup berbagai macam sistem operasi. SIJALU menggunakan sistem operasi Linux Ubuntu 14.04 sehingga kompatibel dengan BackupPC. Lokasi server yang digunakan berada di layanan cloud Digital Ocean dengan lokasi node berada di Singapura. Rancangan topologi yang akan dibangun dalam penelitian ini dapat terlihat pada Gambar 1. Pada topologi tersebut, server SIJALU merupakan virtual server yang berada pada Cloud Server USM. Selain SIJAL.U terdapat 15 virtual server lainnva, namun dalam gambar tersebut penulis berikan ilustnisi sebanyak 3 virtual server saja. Backup Server berlokasi di DigitalOcean yang nantinva akan terhubung dengan Cloud Server USM dengan model autentikasi SSH.

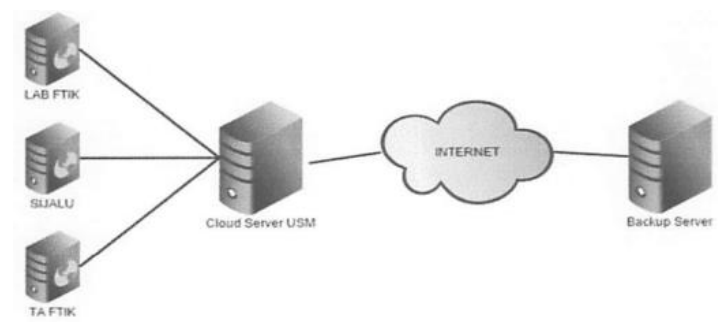

Gambar 1 Desain Topologi Jaringan Backup

Model autentikasi SSH dipilih karena faktor keamanan yang baik dan kerap digunakan untuk menghubungkan antar server. Untuk itu akan dilakukan pembuatan ssh-key dari Backup Server kemudian ditambahkan ke server SIJALU sehingga nantinya aplikasi BackupPC dapat langsung berkomunikasi dengan SIJALU tanpa perlu melakukan autentikasi kembali.

\section{Implementasi}

Tahap berikutnya adalah implementasi (implement) [7], yang akan menjalankan dari tahap rancangan sebelumnya. Langkah pertama adalah menyiapkan server DigitalOcean dengan sistem operasi Linux Ubuntu 14.04 dan lokasi berada di Singapura. Spesillkasi yang digunakan adalah 1 CPU, RAM 512 MB, SSD Disk 20 GB, dan 1 TB bandwidth transfer. Langkah selanjutnva adalah memulai proses instalasi BackupPC pada server, adapun untuk proses instalasi menggunakan bantuan aplikasi PuTTY untuk akscs remote ke server yang berlokasi di Singapura. Nantinya proses instalasi akan menggunakan CLI (Command Line Interface ).

Membuat SSH-Key untuk memberikan autentikasi antara Backup Server dengan SIJALU. SSH-Key berfungsi supaya saat proses komunikasi antar .Server dapat langsung terhubung dan terkoneksi dengan aman karena telah divalidasi dengan protokol SSH. Secara teknis, dilakukan switch account dengan nama "backuppc", seperti terlihat pada Gambar 2.

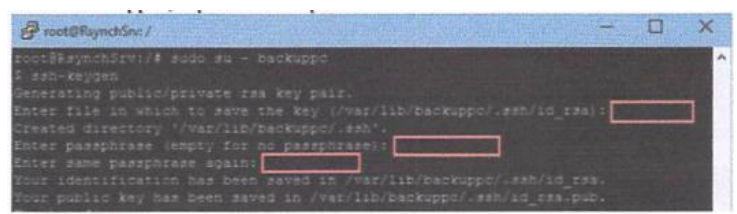

Gambar 2 Pembuatan SSH-Key

Setelah SSH-Key berhasil tercipta. maka langkah selanjutnva mengirimkan key tersebut ke server SIJALU supaya akun "backuppc " dapat langsung mengakses server SIJALU dan memindahkan ssh-key kc akun root pada server cloud.usm.ac.id melalui port 22113. Pada tahap ini, muncul permasalahan karena adanya file konfigurasi BackupPC tidak dapat terintegrasi dengan Apache2 yang menyebabkan ketika URL tersebut diakses, web browser tidak menampilkan halaman web namun mengunduh file dari server.

Untuk mengatasi permasalahan tersebut dilakukan penghapusan file backuppc.conf pada modul Apache2, kemudian melakukan symlink* file apache.con/ pada folder backuppc ke file backuppc.conf yang telah dihapus tadi. Final dilakukan restart pada service Apache supaya perubahan dapat segera diimplementasikan.

\section{Pengoperasian}

Tahap kelima dalam PPDIOO adalah pengoperasian (operate) [7], dimana pada tahap ini penulis mengkonfigurasi dan menjalankan aplikasi BackupPC untuk mulai melakukan backup terhadap SIJALU. Langkah pertama yaitu mengkonfigurasi BackupPC supaya terhubung dengan SIJALU dengan memilih menu Edit Hosts kemudian menambahkan IP dari SIJALU yaitu 10.0.0.10 dengan nama user backuppc yang tadi telah dibuatkan ssh-key. Selanjutnva melakukan konfigurasi pada menu Xfer untuk menentukan metode transfer yang digunakan. Seperti yang telah dibahas pada bab Perencanaan.

Pada penelitian digunakan Rsync sebagai protokol remote backup dari server SIJALU menuju Backup Server. Langkah kedua adalah mulai melakukan Full Backup, sebagai

inisialisasi awal sekaligus mcmastikan bahwa konfigurasi yang dilakukan scbelumnya telah berhasii. Langkah ini juga sebagai penanda bahwa aplikasi BackupPC telah siap untuk digunakan.

\section{Optimasi}

Tahap terakhir dalam PPDIOO adalah optimasi (optimize) (Wilkins, 2011) yang bertujuan untuk melakukan optimasi konfigurasi pada aplikasi BackupPC. Adapun optimasi yang bisa dilakukan adalah mengatur penjadwalan backup supaya mendapatkan file backup lebih teratur. Adapun langkah selanjutnva melakukan monitoring terhadap Backup Server dengan memastikan kuota space masih mencukupi dan melakukan perawatan berkala pada Backup Server supaya selalu dalam kondisi prima. 


\section{Pengujian}

Sistem Pengujian yang dilakukan untuk menguji sistem yang berjalan dengan menggunakan pengujian black-box karena yang diuji berupa script bukan source code program. Hasil dari pengujian black-box dapat dilihat dan hasil tabel 1 berikut ini

Tabel 4.1. Hasil Pengujian Black-box

\begin{tabular}{|c|l|l|l|}
\hline No & \multicolumn{1}{|c|}{ Kasus Uji } & \multicolumn{1}{|c|}{$\begin{array}{c}\text { Langkah } \\
\text { Pengujian }\end{array}$} & \multicolumn{1}{|c|}{ Hasil } \\
\hline 1. & $\begin{array}{l}\text { Generate ssh } \\
\text { authentification }\end{array}$ & $\begin{array}{l}\text { Proses } \\
\text { pembuatan ssh } \\
\text { key }\end{array}$ & $\begin{array}{l}\text { Ssh key } \\
\text { tercipta }\end{array}$ \\
\hline 2 & $\begin{array}{l}\text { Connection server } \\
\text { dengan ssh } \\
\text { authentification }\end{array}$ & $\begin{array}{l}\text { Remote } \\
\text { connection } \\
\text { server }\end{array}$ & $\begin{array}{l}\text { Koneksi } \\
\text { tanpa login }\end{array}$ \\
\hline 3 & Full Backup & Proses Backup & $\begin{array}{l}\text { Data } \\
\text { Backup } \\
\text { dalam cloud } \\
\text { server }\end{array}$ \\
\hline 4 & Restoring & $\begin{array}{l}\text { Restoring data } \\
\text { backup }\end{array}$ & $\begin{array}{l}\text { Berhasil } \\
\text { Load }\end{array}$ \\
\hline 5 & Schedule backup & $\begin{array}{l}\text { Ditentukan } \\
\text { penjadwalan } \\
\text { backup } \\
\text { otomatis }\end{array}$ & $\begin{array}{l}\text { Data } \\
\text { Backup } \\
\text { dalam cloud } \\
\text { server sesuai } \\
\text { schedule }\end{array}$ \\
\hline
\end{tabular}

Dari pengujian yang dihasilkan maka dapat ditarik suatu kesimpulan bahvva sistem yang dirancang dan dibangun sudah sesuai dengan kebutuhan backup.

\section{Kesimpulan}

Berdasaikan hasil penelitian yang telah dilakukan, dapat diambil kesimpulan bahwa metode remote connection untuk melakukan backup \& restore dapat dilakukan menggunakan Rsync pada sistem operasi linux. Untuk mempermudah prosesnya, dapat menggunakan aplikasi BackupPC dengan menginstall pada server di luar lingkungan Universitas Semarang. DigitalOcean sebagai penyedia layanan cloud dapat digunakan untuk menjalankan BackupPC dan menyimpan data backup tersebut

\section{Daflar Pustaka}

[1]Cenka, B. A. N., Hasibuan, Z. A. \& Suhartanto, R 2012. The Architecture Of Cloud Computing For Educational Environment In Indonesia. Seminar National Aplikasi Teknologi Informasi (SNATI).

[2] ZHANG, S., ZHANG, S., CHEN, X. \& HUO, X. Cloud computing research and development trend. Future Networks, 2010. ICFN'10. Second International Conference on, 2010. IEEE,93-97.

[3]Suprayogi, M. S. \& Ashari, A. 2014. Implementasi Cloud Computing Menggunakan Model Adopsl Roadmap For

Cloud Computing Adoption (Rocca) Pada Institusi Pendidikan (Studi Kasus Universitas Semarang). Thesis, Universitas Gadjah Mada.

[4]He, Q., Guo, Y., Wang, Y. \& Qiang, B. A Web Site Protection Oriented remote backup and recovery method. Communicationsand Networking in China (CHINACOM), 2013 8th International ICST Conference on, 14-16 Aug. 2013.395-399.

[5]Latta, O. \& Galanda, J. 2013. Data Backup And Restore In The Network Environment. Acta Avionica, 15.

[6]Sampaio, D. \& Bernardino, J. 2015. Open Source Backup Systems For SMEs. In: Rocha, A., Correia, M. A., Costanzo, S. \& Reis, P. L. (eds.) New Contributions in Information Systems and Technologies: Volume I.Cham:Springer International Publishing.

[7] WILKINS, S. 2011. Cisco's PPDIOO Network Cycle [Online]. Cisco Press. Available: httpi/www.ciscopress.com/articles/article.asp?p=1 697888 [Accessed23 April 2015].

[8]Ellingwood, J. 2013. How To Choose An Effective Backup Strategy For Your Vps [Online]. DigitalOcean. Available: https://www.digitalocean.com/community/tutorial s/how-to-choose-an-effective-backup-strategyfor-your-vps [Accessed 10 November 2015]. 